\title{
Dynamic testing of railway metal culvert using geodetic methods
}

\author{
Damian Beben ${ }^{1, *}$ and Wojciech Anigacz ${ }^{1}$ \\ ${ }^{1}$ Faculty of Civil Engineering and Architecture, Opole University of Technology, 45-061 Opole, \\ Poland
}

\begin{abstract}
The objective of the study was to compare and assess suitability of two methods of geodetic measurements (tachymetry i interferometry) used to determine changes of the geometric condition of building and engineering structures. The paper presents the selected results of experimental tests under dynamic loads that were conducted on a railway metal culvert. The dynamic loads were caused by the passages of various trains. The measurements were made for all trains which had been running over the culvert during a 24 hour period. Advantages and disadvantages of both applied methods were characterized. The disadvantage of the tachymetry method is the discreteness of measurements and the lack of the possibility of verifying the results after finishing the field works. The tachymetry measurements were conducted using precise tachymetry manufactured by Leica TC2002. The IBIS microwave coherent radar was used in the interferometry method. Moreover, a special microwave horns IBIS-H23 type with a maximum gain of $23 \mathrm{dBi}$ were used as the interferometer antennas (transmitting and receiving). Conclusions drawn from the tests can be helpful in the measurements of such culverts.
\end{abstract}

\section{Introduction}

Non-destructive measurements like GPS, GPR, thermography, photogrammetry, laser scanning, etc. are more and more popular to diagnostic of various engineering structures [1], [2]. The dynamic and static tests of bridges and culverts are conducted in order to confirm structural specifications, or to provide diagnostic surveys for planning maintenance and modernization. Typical experimental tests are usually carried out using accelerometers, strain and inductive (or dial) gauges. Installing most of these sensors require direct contact with the structure. However, examining structures can cause accessibility problems, often requiring using scaffolds. That is why, authors decided to analyse in this article two measurement methods intended for non-contact monitoring of the construction displacements.

The IBIS-S interferometric radar applied in tests, is a precision microwave instrument suitable to the non-contact vibrations and displacements monitoring of engineering structures. The high accuracy and quickness of measurement are among of the main characteristic features of the radar. The comparison of the interferometric radar vs. the

*Corresponding author: d.beben@po.opole.pl 
accelerometer used for dynamic monitoring of various large bridges is presented in [3-4]. The differences in displacements of bridges were in the order of one-tenth of millimetres. The interferometry method for non-contact dynamic and static measurement of the vibration of various engineering structures (bridges, towers, dams) was described in [5-8].

The main objective of the study was to compare and assess the suitability of two different geodetic measurement methods (interferometric radar and tachymetry) for determination of displacements of railway culvert. Information on the change in the shape of the bridge structures under the service load are very important for a number of reasons. Knowing the changes in the structure shape, the correctness of the project assumptions can be evaluated. Additionally, after some period of exploitation one can obtain information if the bridge displacements do not exceed the code limit.

\section{Short culvert description}

The tested railway culvert in the cross section has two spans in shape of closed arch. The effective length of shells is $L 1=L 2=4.40 \mathrm{~m}$ (Fig. 1). The load bearing structure was constructed as two shells assembled from the corrugated metal plate (CMP) sheets. The corrugation depth of $0.05 \mathrm{~m}$, pitch of $0.15 \mathrm{~m}$ and plate thickness of $0.003 \mathrm{~m}$ were designed. The individual sheets were connected together using high strength bolts $20 \mathrm{~mm}$, and covered with the layers of soil (about $0.20-0.30 \mathrm{~m}$ thick) properly compacted to achive $I_{\mathrm{D}}=$ 0.98 (in the Proctor Normal scale). The soil cover over the CMP structures (including ballast, blanket and backfill) equals $2.40 \mathrm{~m}$. The width of the culvert shell at the top is $B t=$ $16.00 \mathrm{~m}$, whereas at the bottom is $B b=21.80 \mathrm{~mm}$. The height of culverts is $H 1=H 2=$ $2.80 \mathrm{~mm}$. In the plan view, the object is situated perpendicularly to the railway line. On the culvert two rail tracks are arranged, first is electrified and the second is designed for nonelectrified rolling stocks (Fig. 1).

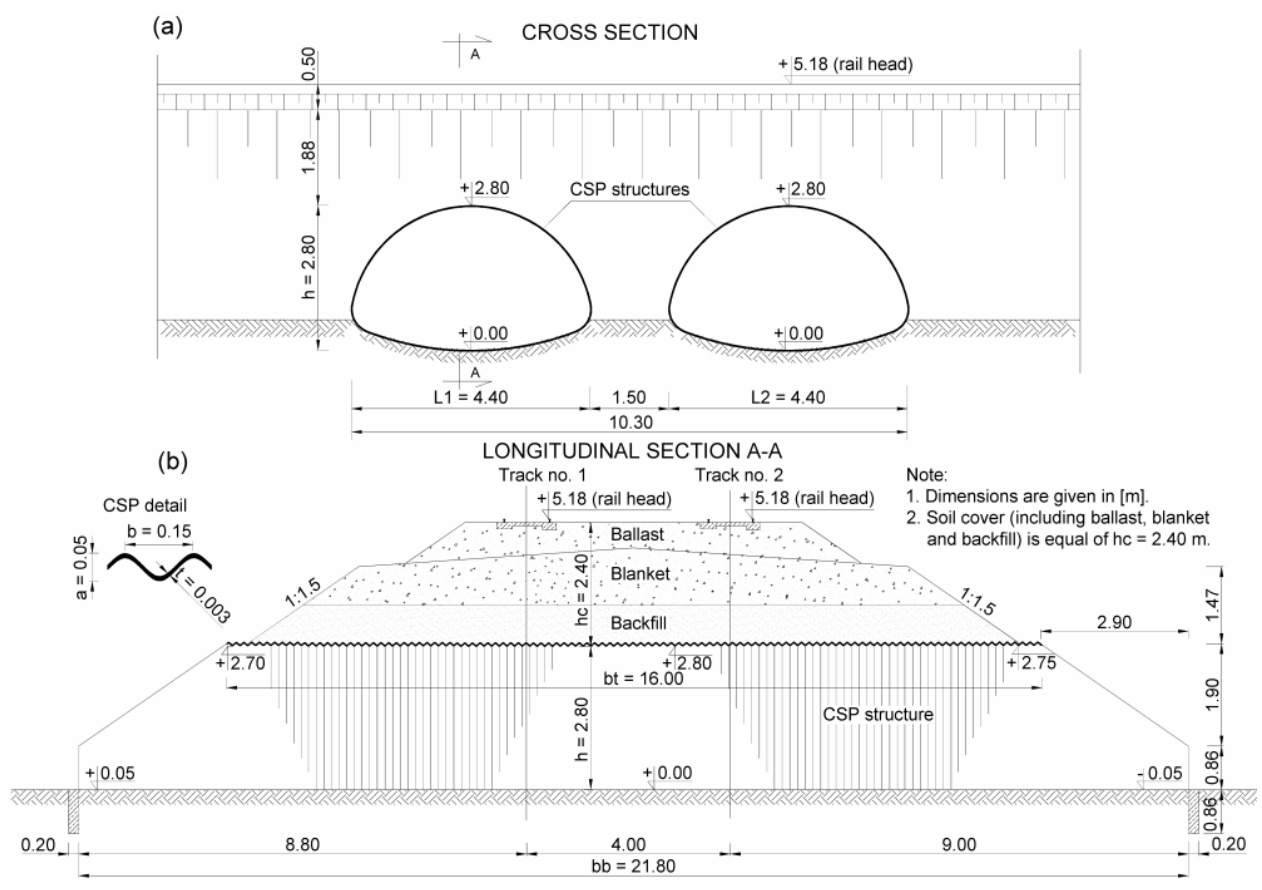

Fig. 1. The corrugated steel plate culvert: a) cross section, b) longitudinal section A-A. 


\section{Background of applied methods}

\subsection{General notes}

Geodesy has a high range of measurement methods, from which we need to choose the most useful ones for measuring deflection of the CMP culvert. One of the most significant factors influencing the selection of the method is the geometric specificity of the bridge. The culvert span is significant because the accuracy of determination if the location of the measurement point decreases with the distance and is described with universal interrelations between the measured values, according to the formula (1):

$$
m_{n}=\sqrt{m_{x}^{2}+m_{y}^{2}+m_{h}^{2}}
$$

where: $m_{n}=$ spatial error, $m_{x}=$ error of the coordinate $x=d \cdot \sin z \cdot \sin \alpha, m_{y}=$ error of the coordinate $y=d \cdot \sin z \cdot \cos \alpha, m_{h}=$ error of the coordinate $h=d \cdot \cos z, \alpha=$ horizontal angle, $z=$ vertical angle (zenithal), $d=$ slant distance.

The experimental tests were carried out after thirteen years of service of the culvert. The culvert displacements were registered during normal service, continuously for 24 hours. On the examined culvert structure, two measurement methods were tested, i.e.: (i) tachymetry, and (ii) interferometric radar. Based on this methods, the displacements of the culvert were determined.

\subsection{Radar technique}

A coherent microwave beam with a very low power and variable frequencies is emitted by the microwave interferometric radar in direction of the tested object. Next, the reflected signal is received and analysed. Displacements of the reflector are detected and recorded only in the radial direction. The high accuracy of measurements makes possible to carry out tests under conditions in which the displacements are not parallel to the axis of the microwaves beam. It is possible in the case when the change of radial distance is not less than $10 \%$ of the real displacements. It means that the angle between the direction of the microwaves beam axis and the direction of displacements should not exceed $84^{\circ}$.

In these experimental studies, the distance from the radar to the microwave reflector was $14.5 \mathrm{~m}$ (bin =34). The instrument performed recording with a frequency of $94.26 \mathrm{~Hz}$ in all sectors up to a distance of $30 \mathrm{~m}$, i.e. for 60 sectors. It was a compromise between the expected range of vibration frequencies and the amount of data recorded. At the stage of

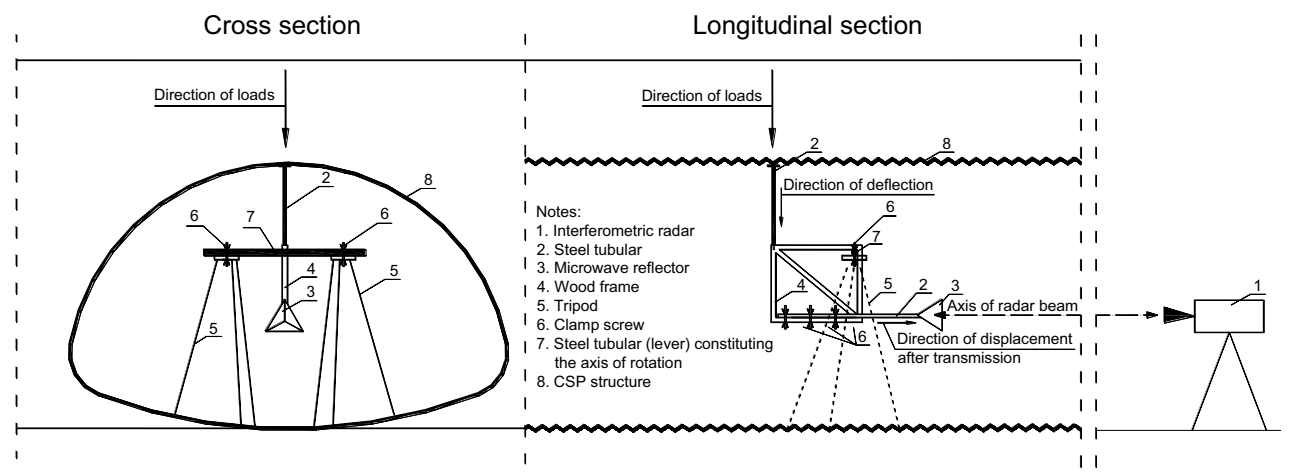

Fig. 2. The "transmission gear" used to experimental tests. 
results working out it turned out that frequencies had not exceeded $15 \mathrm{~Hz}$. Typical conditions for the radar measurements could not be fulfilled in the case of this CMP culvert. Thus, a special "transmission gear" must be used. Thanks to this mechanism, the vertical displacements of the culvert were transformed into the horizontal displacements. Such "transmission gear" was specially constructed (Fig. 2). The mechanism operation is based on the assumption that "transmission gear" acts as a lever with one axis of rotation. As a result of preliminary control testing in the lab and field it was found that the specially constructed mechanism was operated in a satisfactory manner.

The tested railway culvert was made from corrugated metal plates (pitch of $150 \mathrm{~mm}$ ). Such shape of the structure could potentially result in the signal reflections from the multisurfaces. As a result of this phenomenon, the measurement signals reflected from the reflector might be drowned out. In order to reduce the risk of drowning out the signals, the measurement beam of microwaves was placed horizontally (close to the axis of the culvert). Moreover, a special microwave horns IBIS-H23 type with a maximum gain of $23 \mathrm{dBi}$ were used as the interferometer antennas (transmitting and receiving). During the measurements, it turned out that the signals reflected from the reflector significantly dominated by the noise caused by other sources. The dynamic characteristics of "transmission gear" and the reflector were also determined. It was an extremely important problem, because it was necessary to distinguish the displacements spectra between the "transmission gear" and the metal culvert. For this purpose, the pre-tests in several trials were conducted. The frequencies were equal to $8.8 \mathrm{~Hz}$, and they were damped after about 5 seconds. Therefore, in the main test of displacements caused by passing trains, the frequencies varying from 8.5 to $10.0 \mathrm{~Hz}$ were considered as the natural vibration frequencies of the system "transmission gear" - reflector. Details were presented in [9].

\subsection{Tachymetry method}

The tachymetry method depends on the field determination of the spatial polar coordinates, i.e. distances and vertical and horizontal angles from the set of chosen directions. The accuracy of the determination of the point's position is described by the formula (1). Tachymeters are available theoretically measuring the distances with the accuracy of $1 \mathrm{~mm}$ and the directions with the accuracy of 0.5 " ( 0.15 mgon). The accuracies obtained under the field conditions are usually much lower and oscillate within the range of $1-5 \mathrm{~mm}$ for the distances and 3-10" for the determination of the directions.

The angular resolution of the measurement device has high significance especially for the identification of details, e.g. edges in the case of big distances [10-11]. In the analysed

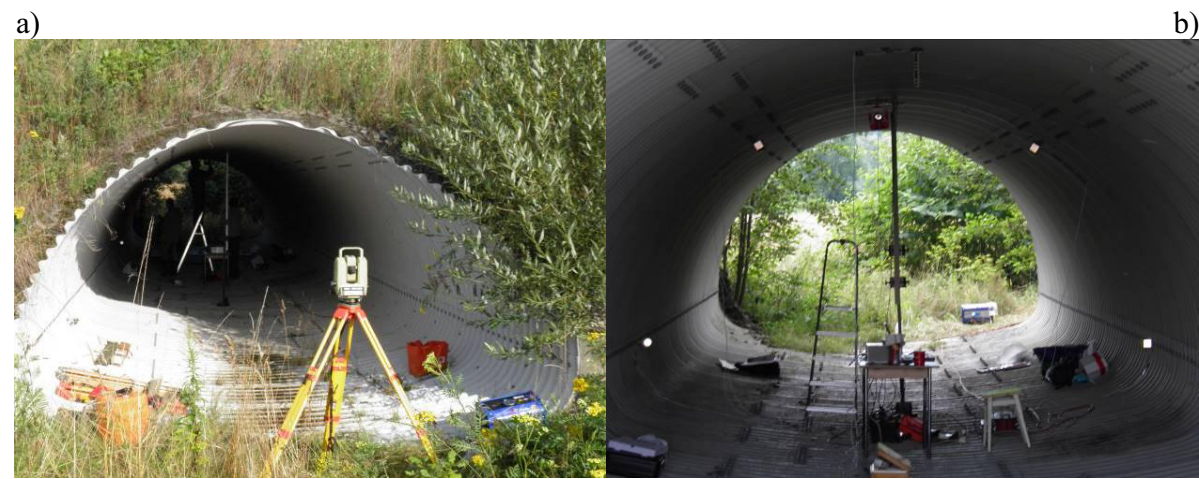

Fig. 3. View on the measurement site using tachymetry method (a) and measurements points installed on the culvert (b). 
case, the stations of the tachymeter were placed on both sides of the river in order to lower the target lengths, i.e. distances between the tachymeter station and the measurement point. In the presented case the distances did not exceed $10 \mathrm{~m}$ (Fig. 3a).

Despite of such a significant difference between the accuracies obtained in the laboratory conditions and in the field conditions, the tachymetry method is currently the most accurate method of determining the position of the points in space [11]. The characteristic feature of this method is the measurement's discreteness. For the studies, the total station TC2002 manufactured by Leica was used and dozen or so different measurement targets (Fig. 3b). Calculations of the displacements were conducted using the authors' programmes [12].

The results obtained with this method were adopted as the reference data for the remaining methods. The correctness of the obtained results of displacements were verified by a measurement from the second station. In order to identify the measured displacements of the bridge, two-sided telemeter targets were used that enabled measurement of the distance from both sides of the target. The measurement targets were placed in the five points under the railway line (Fig. 3b). The opening in the middle of the target has $5 \mathrm{~m}$ diameter. On that basis, it can be concluded that the accuracy of aiming (measurement the direction) was between $0.5-1 \mathrm{~mm}$.

\section{Results of measurements and their analysis}

The experimental tests were conducted in one cross section (in crown directly under the railway line) of the metal culvert where the maximum displacements and vibration frequencies were expected. The experimental tests were conducted continuously for 24 hours. The forty-one various trains were noticed (eighteen - passenger, eighteen - freight, five - others). Fig. 4a shows the metal railway culvert during tests by using the interferometric radar and tachymetry methods. The total loads of tested culvert amounted to: the passenger trains $-32006 \mathrm{kN}$, the freight trains $-144211 \mathrm{kN}$, and others $-4002 \mathrm{kN}$. Simultaneously, it should be pointed, that the maximum weight of the passenger train amounted to $3236 \mathrm{kN}$, and the freight train $-16867 \mathrm{kN}$. The maximum length of the passenger train equalled $178 \mathrm{~m}$, and the freight train amounted to over $520 \mathrm{~m}$. The maximum speeds of passing trains were: $12.5 \mathrm{~m} / \mathrm{s}$ for the freight trains and $33.3 \mathrm{~m} / \mathrm{s}$ for the international passenger trains.

In order to evaluate the possibility of geodetic methods application, at the same time, the interferometric radar, tachymetry method and inductive gauge were used. A European

a)

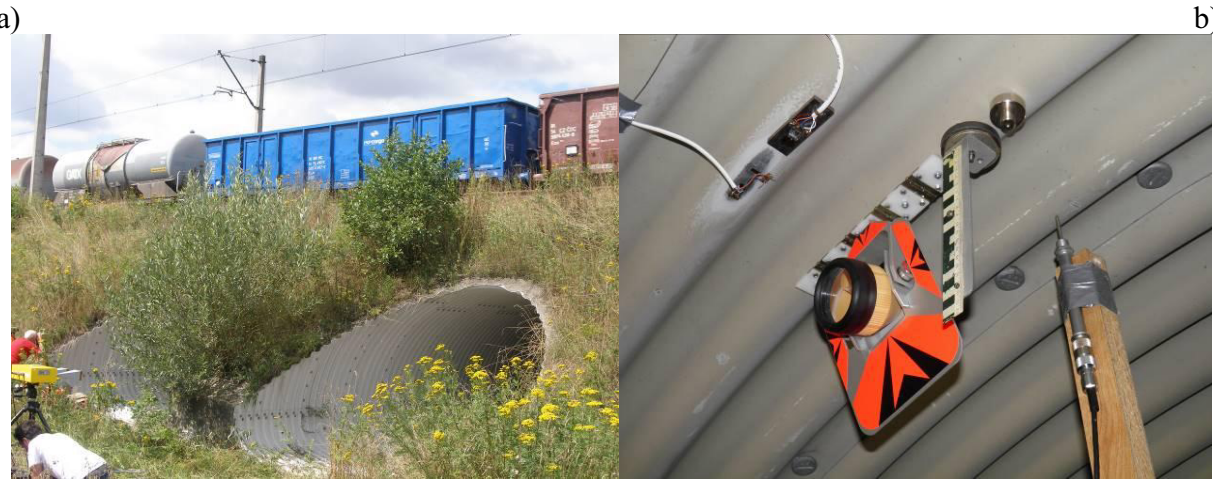

b)

Fig. 4. View on : a) the metal culvert under dynamic tests and b) the inductive gauge for deflection measurements. The targets to geodesic measurements and the extensometers to strain measurements can also be seen. 
patent no. EP 2116806 B1 for fixing a target plate (mirror) was applied [13] (Fig. 4b).

The inductive gauge and measurement targets were placed in the same cross section of the metal culvert in which the special "transmission gear" was fixed. So, three independent techniques for deflection measurements of the metal culvert were applied.

The vertical displacements of the metal shell culvert were measured during conducted experimental tests using interferometric radar (IR) and tachymetry (T). Results using inductive gauges were presented in [9], [14]. The vibration frequencies of the metal culvert were also recorded using the radar.

Fig. 5 shows example of displacements of the crown of metal culvert. The effect of each axle of the freight train can actually be also observed from the displacement versus time plots. The total weight of passing train was $11846 \mathrm{kN}$. During train rides, four main phases of displacements were emphasized. The first phase represents impact of locomotive and two heavy wagons. The maximum displacements amounted to $f_{\mathrm{IR}}=0.53 \mathrm{~mm}$. The second phase relates to passage of four lighter wagons. In this stage the maximum displacements equalled almost $f_{\mathrm{IR}}=0.15 \mathrm{~mm}$. The third phase represents impact of eight heavy wagons. The largest displacements amounted to $f_{\mathrm{IR}}=0.22 \mathrm{~mm}$. The fourth phase relates to vibration reduction (damping) after passage of the freight train.

Application of interferometric radar allows to obtain culvert frequencies. Taking into account displacements presented on Fig. 5 (passage of freight train), the frequencies were determined. In the first phase represents impact of locomotive and two heavy wagons the

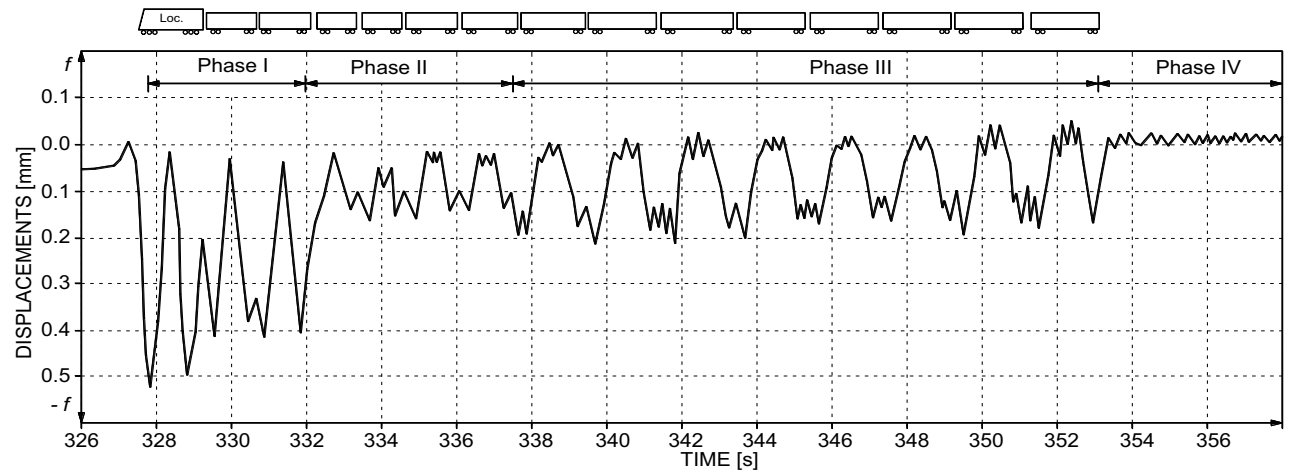

Fig. 5. The courses of vertical displacements measured using the interferometric radar during passage of the freight train.
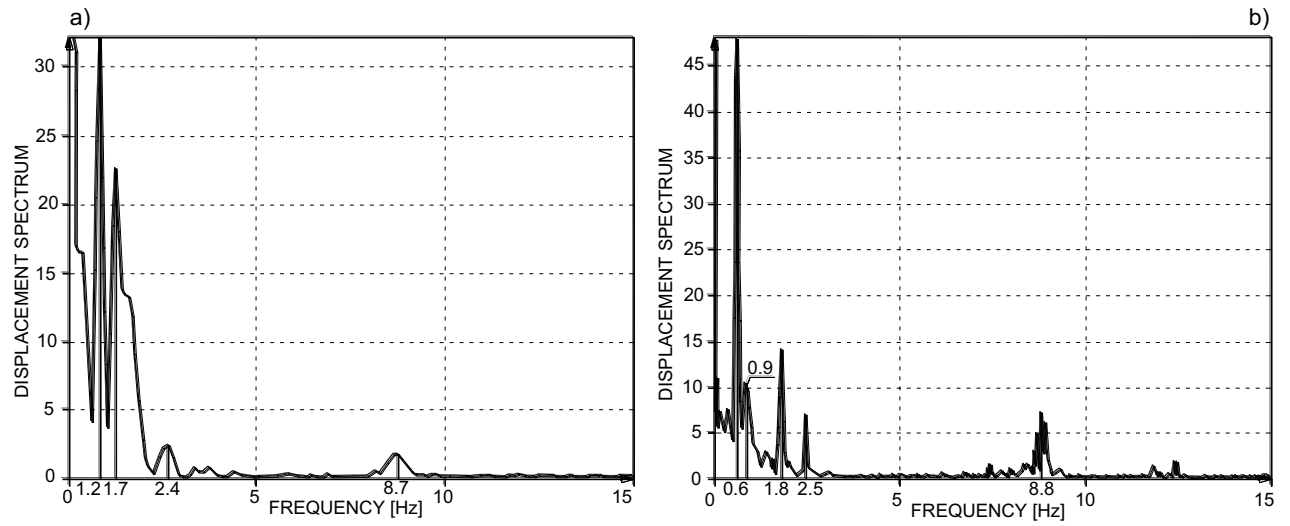

Fig. 6. Spectra of displacements measured using radar at the crown of metal culvert in phase: a) I and b) III, for passage of the freight train. 
highest frequencies were 1.2 and $1.7 \mathrm{~Hz}$ (Fig. 6a). In the third phase represents impact of eight heavy wagons the largest frequencies were $0.6 \mathrm{~Hz}$ (less distinct frequencies were 0.9 , 1.8 and $2.5 \mathrm{~Hz}-$ Fig. 6b). In the fourth phase (vibration damping after passage of the freight train) the dominate frequencies were in the range of 8.7-8.9 $\mathrm{Hz}$ which were identified, according to the preliminary tests, as a natural frequency of the "transmission gear".

Generally, the maximum vertical displacements of the culvert crown do not exceed $f_{\mathrm{IR}}=$ $0.65 \mathrm{~mm}$ and $f_{\mathrm{T}}=0.7 \mathrm{~mm}$. Displacements received from the interferometric radar were smaller than those obtained from tachymetry method in range of $7-25 \%$. The maximum vertical displacements of the metal culvert crown received from all passing trains using the interferometric radar and the tachymetry method are shown in Fig. 7. Comparing the displacements received from inductive gauge with ones from the interferometry method, they are almost the same. They were obtained during passage of the heavy freight trains. Then, the smallest deflection of the culvert registered during tests was $f_{\mathrm{IR}}=0.08 \mathrm{~mm}$. The typical response of the metal railway culvert to passing trains is usually the collection of three frequencies in the range of 0.6 to $3.0 \mathrm{~Hz}$. The highest values of frequencies were caused by passage of the express trains (speed was varying from 70 to $120 \mathrm{~km} / \mathrm{h}$ ).

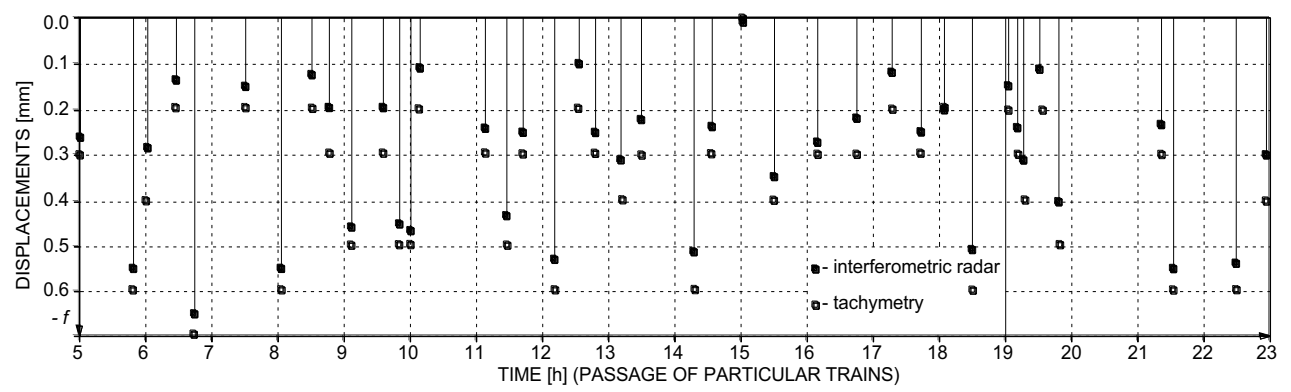

Fig. 7. Maximum displacements on the metal culvert crown using the applied methods.

The metal culvert responds to change of loads very fast. The displacements decrease immediately after passages of trains. The maximum measurement results of the metal culvert using the interferometric radar were quite similar to results received using the tachymetry method (the differences did not exceed $25 \%$ ). Taking into account the defects of tachymetry method, the results are quite good. Such differences can be caused by manual estimation of the displacement values. The interferometric radar correctly responds to rapid and frequent change of loads. The natural vibrations of shell structure were not observed. It is probably caused by large thickness of the backfill placed around steel shell structure which in this case is a damper of vibration.

\section{Conclusions}

As a result of the experimental tests, carried out on the metal railway culvert using geodetic methods, the following conclusions can be drawn:

1. The interferometric radar is a suitable measurement instrument to long-term monitoring of small-to-medium culverts or bridges. It allowed to get the displacements and frequencies of this specific type of the metal culverts very fast and with a high accuracy level. The interferometric radar registered even very small values of displacements and frequencies of the metal culvert (with an accuracy in the order of $0.01 \mathrm{~mm}$ and $0.1 \mathrm{~Hz}$ respectively). The special "transmission gear" need to be used during testing of small culverts and bridges. This necessity results from the possibility of drowning out the 
signal by the corrugation surfaces. Generally, the application of the specially constructed "transmission gear" did not influence measurement results significantly.

2. Tachymetry method allows to obtain the higher culvert crown displacements (max. $25 \%$ ) than those received using interferometric radar. Such differences can be caused by manual estimation of the displacement values in the tachymetry method. Tachymetry method does not allow to obtain the frequency of the culvert.

3. During experimental tests under service loads any irregularities of behaviour of the metal railway culvert were not found after thirteen years of service. The highest dynamic response of this culvert has been mostly caused by passages of freight trains and passenger express trains. Other types of trains, i.e. slow passenger trains, maintenance-repair trains, locomotives have not a significant dynamic impact on the metal culvert.

\section{References}

1. D.M. McCann, M.C. Forde, Review of NDT methods in the assessment of concrete and masonry structures, NDT\&E Int. 34, 71-84 (2001)

2. D. Beben, A. Mordak, W. Anigacz, Ground penetrating radar application to testing of reinforced concrete beams, Procedia Eng. 65, 242-247 (2013)

3. M. Pieraccini, M. Fratini, F. Parrini, C. Atzeni, G. Partoli, Interferometric radar vs. accelerometer for dynamic monitoring of large structures: An experimental comparison, NDT\&E Int. 41, 258-264 (2008)

4. C. Gentile, G. Bernardini, Output-only model identification of a reinforced concrete bridge from radar-based measurements, NDT\&E Int. 41, 544-553 (2008)

5. D. Dei, M. Pieraccini, M. Fratini, C. Atzeni, G. Bartoli, Detection of vertical bending and torsional movements of a bridge using a coherent radar, NDT\&E Int. 42, 741-747 (2009)

6. C. Gentile, Deflection measurement on vibrating stay cables by non-contact microwave interferometer, NDT\&E Int. 43, 231-240 (2010)

7. M. Fratini, F. Parrini, M. Pieraccini, C. Borri, C. Atzeni, Structural oscillation modes identification by applying controlled loads and using microwave interferometry, NDT\&E Int. 42, 748-752 (2009)

8. M. Pieraccini, F. Parrini, M. Fratini, C. Atzeni, P. Spinelli, M. Micheloni, Static and dynamic testing of bridges through microwave interferometry, NDT\&E Int. 40, 208214 (2007)

9. D. Beben, Application of the interferometric radar for dynamic tests of corrugated steel plate (CSP) culvert, NDT \& E Int. 44, 405-412 (2011)

10. A.Berenyi, T. Lovas, A. Barsi, L. Dunai, Potential of terrestrial laser scanning in load test measurements of bridges, Period. Polytech. 53, 25-33 (2009)

11. T. Luhmann, Ch. Müller, Photogrammetrie Laserscanning Optische 3D-Messtechnik (Heidelberg: Herbert Wachman Verlag, 2007)

12. W. Anigacz, D. Beben, J. Kwiatkowski, Analysis of suitability of new measurement technologies to examine changes in geometric parameters of a suspension bridge, Maintenance, Monitoring, Safety, Risk and Resilience of Bridges and Bridge Networks (Eds. T.N. Bittencourt, D.M. Frangopol, A. Beck, 2204-2211, 2016)

13. W. Anigacz, A target fixing device, Patent no. EP 2116806 B1. European Patent Office. Munich (2012)

14. D. Bęben, W. Anigacz, Interferometric radar application for dynamic testing of bridge structures, Bridge Maintenance, Safety, Management and Life Extension (Eds. A. Chen, D.M. Frangopol, X. Ruan, 2289-2296, 2014) 